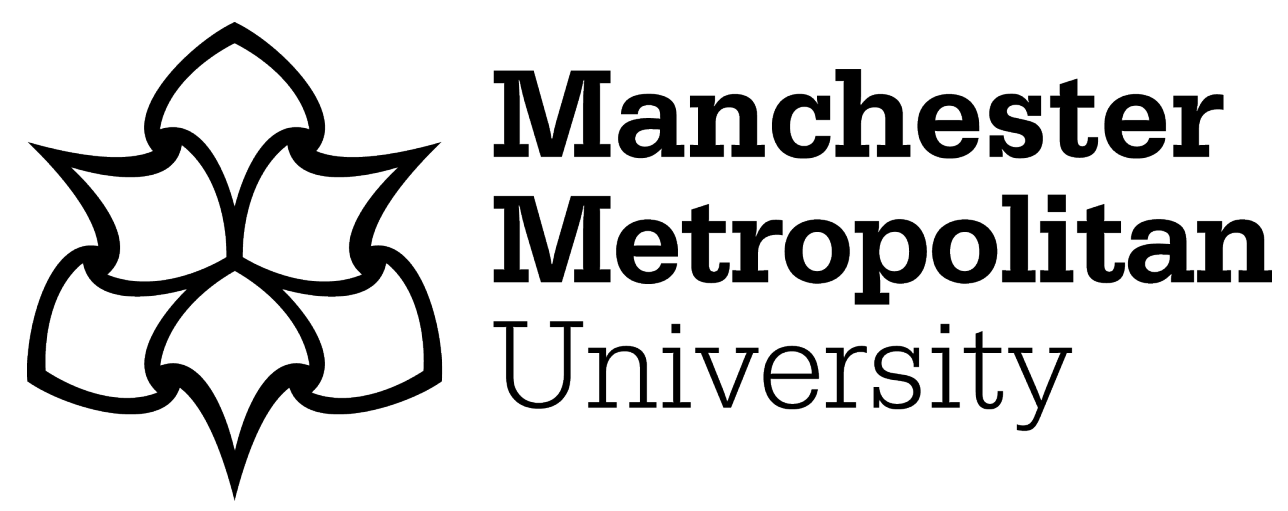

Kamieniak, J, Kelly, PJ, Doyle, AM and Banks, CE (2018) Influence of the metal/metal oxide redox cycle on the catalytic activity of methane oxidation over Pd and Ni doped hydroxyapatite. Catalysis Communications, 107. pp. 82-86. ISSN 1566-7367

Downloaded from: https://e-space.mmu.ac.uk/623890/

Version: Accepted Version

Publisher: Elsevier

DOI: https://doi.org/10.1016/j.catcom.2017.12.017

Usage rights: Creative Commons: Attribution-Noncommercial-No Derivative Works 4.0

Please cite the published version 


\section{Accepted Manuscript}

Influence of the metal/metal oxide redox cycle on the catalytic activity of methane oxidation over $\mathrm{Pd}$ and $\mathrm{Ni}$ doped hydroxyapatite

Joanna Kamieniak, Peter J. Kelly, Aidan M. Doyle, Craig E.

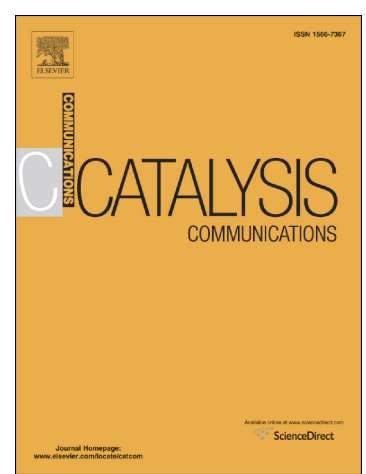
Banks

PII: S1566-7367(17)30497-1

DOI: doi:10.1016/j.catcom.2017.12.017

Reference: CATCOM 5273

To appear in: Catalysis Communications

Received date: 8 July 2017

Revised date: 2 December 2017

Accepted date: 23 December 2017

Please cite this article as: Joanna Kamieniak, Peter J. Kelly, Aidan M. Doyle, Craig E. Banks, Influence of the metal/metal oxide redox cycle on the catalytic activity of methane oxidation over Pd and Ni doped hydroxyapatite. The address for the corresponding author was captured as affiliation for all authors. Please check if appropriate. Catcom(2017), doi:10.1016/j.catcom.2017.12.017

This is a PDF file of an unedited manuscript that has been accepted for publication. As a service to our customers we are providing this early version of the manuscript. The manuscript will undergo copyediting, typesetting, and review of the resulting proof before it is published in its final form. Please note that during the production process errors may be discovered which could affect the content, and all legal disclaimers that apply to the journal pertain. 


\title{
Influence of the metal/metal oxide redox cycle on the catalytic activity of methane oxidation over Pd and Ni doped hydroxyapatite
}

\author{
Joanna Kamieniak*, Peter J. Kelly, Aidan M. Doyle, and Craig E. Banks
}

Faculty of Science and Engineering, Manchester Metropolitan University, Chester Street, Manchester M1 5GD, UK

*To whom correspondence should be addressed.

Email:j.kamieniak@mmu.ac.uk 


\begin{abstract}
The methane oxidation reaction was investigated over $\mathrm{Pd}$ and $\mathrm{Ni}$ doped hydroxyapatite (HAP) catalysts. All catalysts were evaluated in both their reduced and oxidised forms, and the behaviour of the metals in the reaction was investigated. The obtained results demonstrated that the reaction proceeds through a redox cycle between metal oxide and reduced metal, however more stable catalysts with higher conversions were observed when the catalysts were pre-treated in oxygen. After $\mathrm{CH}_{4}$ oxidation, all the samples were tested towards coke formation using TGA analysis; results showed that all the catalysts were resistant to the coking process under the conditions studied.
\end{abstract}

Keywords: Hydroxyapatite; Methane oxidation; Catalysis; Coke formation 


\section{Introduction}

Chemical reactions that take place during the oxidation of methane are governed by the thermodynamics of their reaction equilibria.[1] However, in the system where there is more than one equilibrium, there may be several possible different routes to obtain the desired products and/or by-products through side reactions (Figure 1). Nevertheless, the major limitations of the oxidation of methane are safety issues regarding pure oxygen, which is considered as highly dangerous in industrial applications. Moreover, the high temperatures required to activate methane and oxygen make the reaction very difficult to control, where hot spots are formed on the surface of the catalyst, leading to local overheating and reduced stability, thus there is a constant need to develop stable catalysts that will be highly active in lower temperatures $\left(<500^{\circ} \mathrm{C}\right)$.[2]

Noble metals, mostly $\mathrm{Pt}, \mathrm{Pd}, \mathrm{Rh}, \mathrm{Ru}$ and Ir have been extensively studied on numerous supports, and have reported high catalytic activity towards methane, as summarised in an excellent recent review.[3] Nevertheless, due to the high cost and limited accessibility of noble metals, various transition metals, like $\mathrm{Ni}, \mathrm{Fe}, \mathrm{Zr}$ and $\mathrm{Co}$ have also been investigated. From a comparison of different noble and transition metals, however, $\mathrm{Pd}$ and $\mathrm{Ni}$ have been found to be the most active for this reaction.[4] Regarding different supports, numerous mesoporous materials have been studied due to their unpredictable intrinsic structural features, such as tunable pore diameter and good flexibility to accommodate metals onto the surface.[5]

During methane oxidation, the conversion of $\mathrm{PdO}$ to $\mathrm{Pd}$ has a profound effect on the catalytic activity.[6-8] At low temperatures, $\mathrm{PdO}$ is thought to be the phase that is more catalytically active for methane oxidation and the transformation from $\mathrm{PdO}$ to $\mathrm{Pd}$ generally leads to a decrease in catalyst performance as the temperature increases.[9] Such a reaction is observed due to a redox cycle between the metal oxide and the reduced metal. However, Zhang et al. claimed that the highest catalytic activity is observed when the catalyst contains both $\mathrm{Pd}$ and $\mathrm{PdO}$, and the presence of $\mathrm{Pd} / \mathrm{PdO}$ interfaces generate oxygen mobility that is beneficial for $\mathrm{CH}_{4}$ oxidation.[10] Nevertheless, understanding and controlling the phase transformations of metal based catalysts during methane oxidation is crucial and, thus, remains a subject of scrutiny.

Calcium hydroxyapatite (HAP, $\left.\mathrm{Ca}_{10}\left(\mathrm{PO}_{4}\right)_{6}(\mathrm{OH})_{2}\right)$ is a bifunctional material with both acidic and basic properties that is employed as a catalyst and a support for metallic catalysts.[11-13] Sugiyama et al. have extensively reported various stoichiometric forms of apatites and their excellent selectivity in partial methane oxidation in the presence and 
absence of tetrachloromethane (TCM).[14] In addition, stoichiometric mesoporous HAP has been recently reported stable after $\mathrm{pH}$, thermal and mechanical disturbances.[15] In fact, activation of methane has been attributed to basic sites present on the surface of the catalyst, therefore stoichiometric mesoporous $\mathrm{HAP}(\mathrm{Ca} / \mathrm{P}$ 1.67) has become extremely attractive support as it is extensively reported to possess hydroxyl groups that are available for the reaction. $[11,12]$

The present work reports on methane oxidation under stoichiometric conditions over Pd and Ni doped HAP, and the behaviour of these metals during the reaction. Special attention is devoted to the influence of the conditions on the transition between metal oxide and reduced metal via reduction and oxidation of the metal species prior to catalysis. After the catalytic performance tests, all catalysts were investigated for coke formation resistance.

\section{Experimental methods}

\subsection{Materials and chemicals}

All chemicals were obtained from Sigma-Aldrich and solutions were made using deionised water with a resistivity not less than $18.2 \mathrm{M} \Omega \mathrm{cm}$.

\subsection{Synthesis of catalysts}

To synthesise mesoporous HAP different soft-templates were employed, such as polyoxyethylene(20) sorbitan monostearate (Tween 60, $26 \mathrm{~g}$ ), nonaoxyethylene dodecyl ether $\left(\mathrm{C}_{12} \mathrm{EO}_{9}, 10.66 \mathrm{~g}\right)$, or a mixture of Tween 60 and $\mathrm{C}_{12} \mathrm{EO}_{9}$ and a hard-template (carbon nanorods), synthesised following the same procedure as reported in our previous study.[16] For soft templates, $\mathrm{Ca}\left(\mathrm{NO}_{3}\right)_{2}(7.88 \mathrm{~g})$ was mixed with $\mathrm{KH}_{2} \mathrm{PO}_{4}(2.72 \mathrm{~g})$, dissolved in water $(26.60 \mathrm{~mL})$ and acidified by concentrated $\mathrm{HNO}_{3}(13.60 \mathrm{~mL})$. This acidic solution was then added to a template and heated to $60^{\circ} \mathrm{C}$ with stirring until a clear solution was formed. The solution was cooled and treated with $\mathrm{NaOH}(0.1 \mathrm{M})$ added dropwise to precipitate HAP at $\mathrm{pH}$ 9.5. The suspension was stirred overnight, filtered, washed with ethanol and water, dried and calcined in air for 5 hours at $550^{\circ} \mathrm{C}$.[17]

For the hard template route, carbon nanorods $(0.6 \mathrm{~g})$ were dispersed in water $(6 \mathrm{~mL})$ using an ultrasonic bath, then added to a solution of $\left(\mathrm{NH}_{4}\right)_{2} \mathrm{HPO}_{4}(0.4 \mathrm{M}, 100 \mathrm{~mL})$ that was stirred at room temperature $\left(18-22^{\circ} \mathrm{C}\right)$ in a beaker. $\mathrm{Ca}\left(\mathrm{NO}_{3}\right)_{2}(0.6 \mathrm{M}, 100 \mathrm{~mL})$ was then added dropwise over one hour. The $\mathrm{pH}$ was maintained through the addition of $\mathrm{NaOH}(0.1$ M) within the range 9.4-9.5. This 'milky' suspension was then stirred overnight. The 
resulting precipitate was filtered, cleaned alternately with water and ethanol three times, dried and calcined in air for 48 hours at $550^{\circ} \mathrm{C}$ using a ramp rate $1^{\circ} \mathrm{C} \mathrm{min}$.

Ion exchange was used to apply metal to the surface of the HAP. HAP (1g) was stirred with a $\mathrm{Pd}$ or $\mathrm{Ni}$ precursor $(50 \mathrm{mg})$ dissolved in water at ambient conditions for 3 days. The precipitate was then filtered, dried at $60^{\circ} \mathrm{C}$ and calcined at $550^{\circ} \mathrm{C}$ for 6 hours. The preparation methods of all catalysts are shown in Table 1.

\subsection{Characterisation of materials}

Microscopic images were recorded using a JEOL 3000F high resolution transmission electron microscope (HR-TEM) at $300 \mathrm{kV}$. X-ray diffraction (XRD) was conducted using a Panalytical X'Pert Powder diffractometer with $\mathrm{Cu} \mathrm{K} \alpha$ radiation $(\lambda=1.5406 \AA)$. Nitrogen adsorption/desorption measurements were obtained using a Micromeritics ASAP 2020 Surface Analyser at $-196{ }^{\circ} \mathrm{C}$. First, samples were degassed under vacuum $\left(\mathrm{p}<10^{-3} \mathrm{~Pa}\right.$ ) for 3 hours at $300^{\circ} \mathrm{C}$. Thermogravimetric analysis (TGA) measurements were recorded using a Perkin Elmer 4000 instrument. X-ray photoelectron spectroscopy (XPS) analysis was performed using Monochromated Al Ka X-ray source (1486.7 eV), Specs PHOIBOS 150 mm hemispherical analyser with 9-channeltron detection.

\subsection{Oxidation of methane}

The catalytic experiments were performed in a fixed-bed quartz reactor (Carbolite type 3216) operated at atmospheric pressure. A feed mixture of $100 \mathrm{ml} \mathrm{min}^{-1}$ comprising $\mathrm{CH}_{4}: \mathrm{O}_{2}: \mathrm{He}$ in the proportions 5:10:85 was used in all catalytic tests(GHSV of 20,000 $\mathrm{ml} \mathrm{h}^{-1}$ $\left.\mathrm{g}^{-1}\right)$. Prior to reaction, each catalyst $(0.2 \mathrm{~g})$ was reduced in a flow of $30 \mathrm{~mL} \mathrm{~min}^{-1} \mathrm{H}_{2}$ for 1 hour at $300^{\circ} \mathrm{C}$. The reaction products were monitored by a Hewlett Packard 5890 series II gas chromatograph connected to a thermal conductivity detector (TCD). Measurements were recorded at $50^{\circ} \mathrm{C}$ intervals (after holding at that temperature for 5 min to avoid obtaining equilibrium between material and oxygen species in the stream) between 200 and $650^{\circ} \mathrm{C}$ using a heating rate of $10^{\circ} \mathrm{C} \mathrm{min}^{-1}$. After the reaction, the same sample of catalyst was allowed to cool in flowing $\mathrm{He}$, then oxidised in $30 \mathrm{~mL} \mathrm{~min}^{-1} \mathrm{O}_{2}$ for 1 hour at $300^{\circ} \mathrm{C}$, and the catalytic reaction was performed, thereafter, following the same procedure described above. The $\mathrm{CH}_{4}$ conversion was calculated as follows: 


$$
\mathrm{CH}_{4} \text { conversion }(\%)=\frac{\left(\mathrm{CH}_{4}\right) \text { in- }\left(\mathrm{CH}_{4}\right) \text { out }}{\left(\mathrm{CH}_{4}\right) \text { in }} \times 100
$$

\section{Results and Discussion}

\subsection{Synthesis and characterisation of catalysts}

A HR-TEM image shown in ESI Figure 1A revealed the characteristic structure of HAP, Then, as presented in ESI Figure 1B, the obtained XRD pattern revealed all the major peaks that correspond to the hexagonal morphology of HAP with the $\mathrm{P}_{3} / \mathrm{m}$ space group (JCPDS 09/0432).[18, 19]

Next, metal precursors were applied to the surface of HAP via a standard ion exchange approach. EDX analysis was performed to investigate average metal loading and revealed 2-3 wt $\%$ for Pd based catalysts and $<6 \mathrm{wt} \%$ of Ni content, summarised in Table 2 . The BET results showed that sample Pd_O_2 exhibited the highest surface area of $114.6 \mathrm{~m}^{2} \mathrm{~g}^{-1}$. It is interesting to note that $\mathrm{Ni}$-based catalysts showed much lower surface areas than those of $\mathrm{Pd}$ loaded HAP, suggesting different interactions between metal and support (Table 2). In view of that, XRD Rietveld analysis was performed to explore the interaction between the $\mathrm{Pd}$ metal and the support. Based on the lattice parameters that corresponded to $a=b=9.4 \AA$ and $\mathrm{c}=6.9 \AA$, which were equal to lattice parameters of unmodified HAP, it was clear that after Pd doping the morphology of HAP remained stable and the introduction of the metal did not disturb the structure, therefore Pd was adsorbed onto the surface of HAP. However, this observation differed from that reported in the literature. For example, Boukha et al. described Pd loaded HAP for butan-2-ol conversion showing that calcium ions were replaced by Pd.[20] Also Indra et al. reported similar substitution in HAP for the Suzuki-Miyaura crosscoupling reaction, however detailed analysis of the structural changes in the HAP was not described.[21] On the other hand, using the same analysis for Ni-doped HAP samples, obtained lattice parameters varied $(\mathrm{a}=\mathrm{b}=\mathrm{c}=4.2 \AA)$ when compared to bare HAP, suggesting that there was a different origin of the interaction between $\mathrm{Ni}$ and $\mathrm{HAP}$, which is in agreement with what was observed via BET. Nevertheless, it is worth noting that the sample with both metals present in the structure of HAP (Pd/Ni_O_1) revealed no lattice interruptions within the HAP, therefore Pd preserved its crystal structure, possibly due to a synergistic effect.

XPS analysis performed on Pd_O_2 sample revealed Pd 3d $\mathrm{d}_{5 / 2}$ doublet at 336.8 eV (ESI Figure 2) and confirmed that $\mathrm{PdO}$ was the form of metal deposited on the surface of HAP. Moreover, doublet $2 \mathrm{p}_{3 / 2}$ at $347 \mathrm{eV}$ corresponded to $\mathrm{Ca}^{2+}$ present in HAP. 


\subsection{Catalytic activity}

All synthesised catalysts were tested in $\mathrm{CH}_{4}$ oxidation using stoichiometric conditions (Equation 2):

$$
\mathrm{CH}_{4}+2 \mathrm{O}_{2} \stackrel{\text { cat, } \mathrm{T}}{\longrightarrow} \mathrm{CO}_{2}+2 \mathrm{H}_{2} \mathrm{O}
$$

As presented in Figure 2A, all the reduced Pd-based samples were catalytically active at low temperatures with the highest conversion obtained of $60 \%$ at $200^{\circ} \mathrm{C}$. However, a loss of catalytic performance was observed at $350^{\circ} \mathrm{C}$. This was due to a redox cycle that occurred between reduced metal and oxidised metal (ESI Figure 3).[22] As a consequence, the diffusion rate of the bulk oxygen in the metal oxides increased with temperature and, hence, the amount of consumed oxygen increased. This was associated with a decrease in the quantity of gas-phase oxygen available for the reaction causing a related drop in conversion. The outlier to this trend was sample Pd_O_2, where the metal redox cycle shifted to $400^{\circ} \mathrm{C}$, suggesting different metal distribution on the support and altered oxygen availability for the metal to be oxidised. Interestingly, Pd_O_2 exhibited the highest surface area of the catalysts reported here, so it was possible that the observed activity drop was a consequence of a greater amount of Pd metal exposed to the reaction. Subsequently, at higher temperatures, the catalytic performance of all samples increased, followed by another drop in the activity between $400-550^{\circ} \mathrm{C}$. Hence, it was clear that among the feed oxygen available in the stream, the adsorbed surface oxygen of the metal oxide was active in the methane oxidation reaction. Therefore, this implied that the oxygen from the metal oxide took part directly in the catalysis, successively forming reduced metal, which then used the oxygen species from the feed of the reaction to re-oxidise back to the metal oxide form, as presented in ESI Figure 3. This observation agreed with what has been reported elsewhere.[10] As the reaction proceeded to higher temperatures, catalytic activity increased for all the samples. On the other hand, Ni-based catalysts revealed a similar catalytic trend to that of Pd-based samples when $\mathrm{Ni}$ was reduced prior to reaction and showed general rise in catalytic activity with increased temperature (Figure 3A). A decrease in catalytic activity was observed at temperatures of $350^{\circ} \mathrm{C}$ and $550^{\circ} \mathrm{C}$ for Ni_O_2, and $450^{\circ} \mathrm{C}$ for Ni_O_1, due to metal $/ \mathrm{metal}$ oxide transformations, which were similar results to those obtained for the Pd catalysts. It is worth noting that the sample with a mixture of both $\mathrm{Pd}$ and $\mathrm{Ni}$ metals demonstrated higher $\mathrm{CH}_{4}$ conversions, when compared to single metal catalysts, showing $100 \%$ conversion of $\mathrm{CH}_{4}$ at $400^{\circ} \mathrm{C}$. This phenomenon can be explained by the presence of more active sites on the surface of the HAP and hence its greater availability for the reaction, as the two metals 
underwent oxidation/reduction reactions, therefore gave rise to amount of oxygen to activate methane oxidation.

After the reaction, the system was cooled down in a stream of $\mathrm{He}$ and then each catalyst was fully oxidised using a continuous flow of oxygen to create strongly bonded oxygen onto the metal. It is interesting to note that after hydrogen reduction the reduced metal catalysts were grey in colour, whereas after oxygen treatment prior to reaction all the catalysts turned brown due to oxidation of the metal. The catalytic reaction was then performed at the same conditions as before. As presented in Figure $2 \mathrm{~B}$, enhanced $\mathrm{CH}_{4}$ conversion was observed as the reaction temperature increased. Nevertheless, at a temperature of $300^{\circ} \mathrm{C}$, all conversions remained practically stable when compared to those at $250^{\circ} \mathrm{C}$, suggesting that the metal began undergoing the aforementioned redox cycle. However, due to the large fraction of bulk $\mathrm{PdO}$ and the oxygen present in the reactant stream, transformation of the metal oxide to reduced metal via the redox cycle was not favourable. This led to more stable catalytic profiles at higher temperatures when compared to reduced metal catalysts. At the highest tested temperature $\left(650^{\circ} \mathrm{C}\right)$, all Pd-based catalysts converted $>80 \%$ of methane. In view of that, oxidised metal catalysts showed greater catalytic performance to that of reduced metal samples. This observation supported the hypothesis described above, that the oxygen species from the metal oxide were directly involved in the catalytic reaction. Similar results were reported by Datye et al. where the $\mathrm{Pd} \leftrightarrow \mathrm{PdO}$ phase transformation during methane oxidation reactions was described.[6] Moreover, they theorised that the observed redox cycle formation of oxide causes surface roughening, and hence, resulted in higher activity of $\mathrm{PdO}$ than reduced $\mathrm{Pd}$ metal, which is consistent with observations described here. In fact, obtained results suggest that there is no necessity for reduced metal in highly active catalyst to activate methane as long as there is its oxide form present. Similar catalytic profiles were observed for Ni-based catalysts, as shown in Figure $3 \mathrm{~B}$, where the oxygen present in the reaction stream suggested that alterations between metal and metal oxide were not favourable, displaying more stable catalytic conversion profiles. It is interesting to note that $\mathrm{CH}_{4}$ conversions of $\mathrm{Ni}$-based catalysts at lower temperatures $\left(200^{\circ} \mathrm{C}\right)$ were higher when compared to Pd-doped samples exhibiting $40-65 \% \mathrm{CH}_{4}$ conversion for $\mathrm{Ni}$ and 5-30\% for Pd samples (Figures 3B and 2B, respectively).

\subsection{TGA analysis}

Finally, after all the catalytic reactions were completed, TGA analysis was performed to investigate coke formation, which is the major lifetime limitation of the catalyst. As 
presented in ESI Figure 4, the results obtained revealed a minimum weight loss, ranging from 1.0 to $3.0 \mathrm{wt} \%$ and 3.0 to $5.0 \mathrm{wt} \%$ for Pd- and Ni-based catalysts, respectively. Even though non-noble metals have been previously described in the literature as less resistant to coke deposition in catalytic reactions[23], the reported here Ni-based catalysts showed very low weight loss under oxygen rich reaction environment. Such low values obtained suggested that all the samples were resistant to the coking process under the conditions studied.

\section{Conclusions}

This paper has explored the methane oxidation reaction under stoichiometric conditions over $\mathrm{Pd}$ and $\mathrm{Ni}$ on mesoporous hydroxyapatite. The results obtained demonstrated that the reaction proceeded via a redox cycle between metal oxide and reduced metal. Moreover, oxidised metal was found to be more active than the reduced metal and exhibited more stable $\mathrm{CH}_{4}$ conversions throughout the temperature ramp, suggesting that, along with the oxygen present in the reactant stream, adsorbed surface oxygen took a direct part in the methane oxidation reaction. TGA analysis revealed that all tested catalysts were resistant to coke formation under the conditions studied.

\section{Acknowledgment}

The authors would like to acknowledge G-Volution ltd. for their support and contributions to this research. Also, the authors are grateful to the Facility of Analysis and Characterisation of Solids and Surfaces of SAIUEx (University of Extremadura, Spain) for their assistance with XRD analysis. 
Figure 1. Proposed reaction mechanism of methane over the catalyst in presence of oxygen.

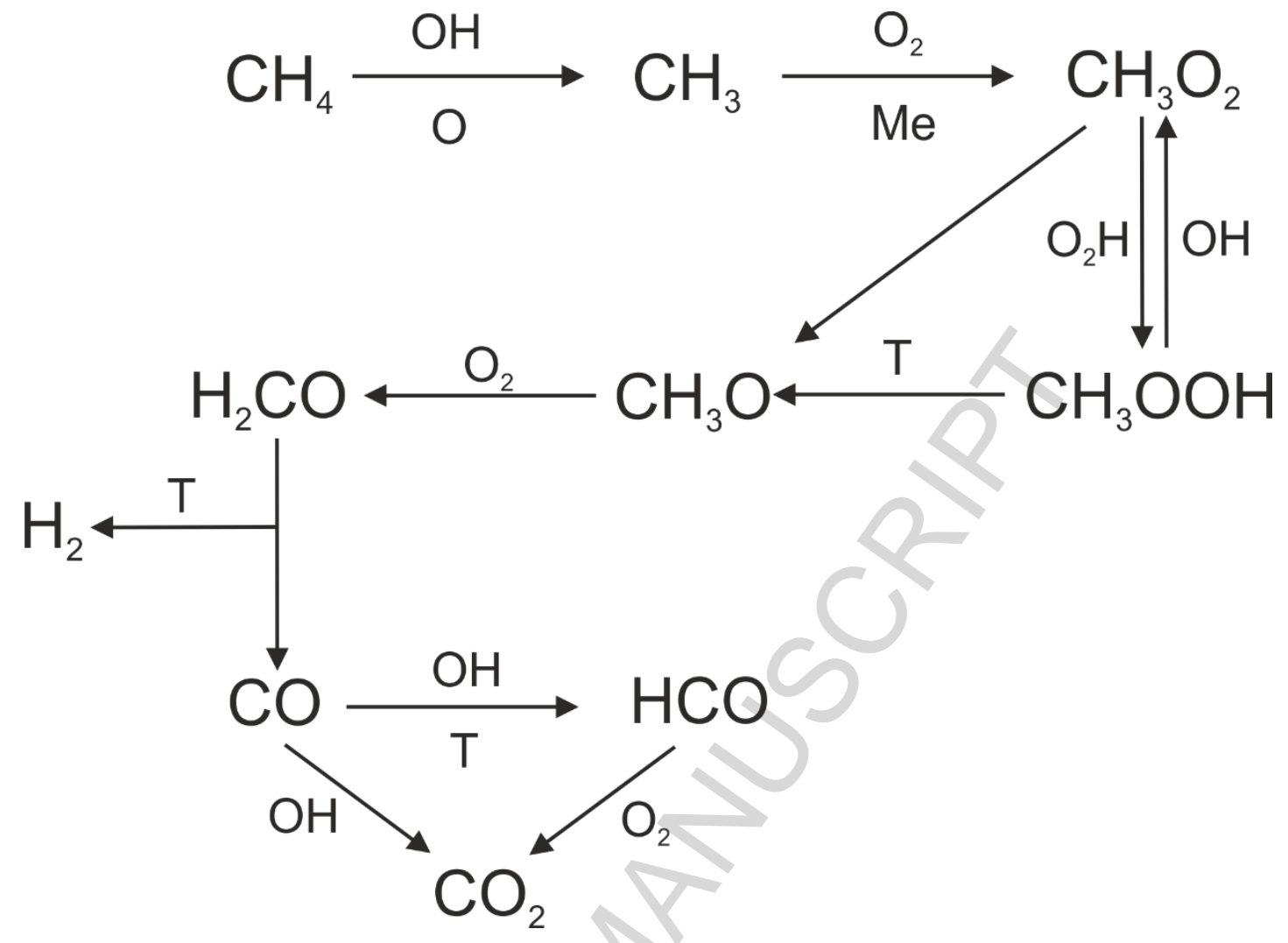


Figure 2. Methane oxidation of Pd based catalysts as reduced metal (A) and oxidised metal (B).
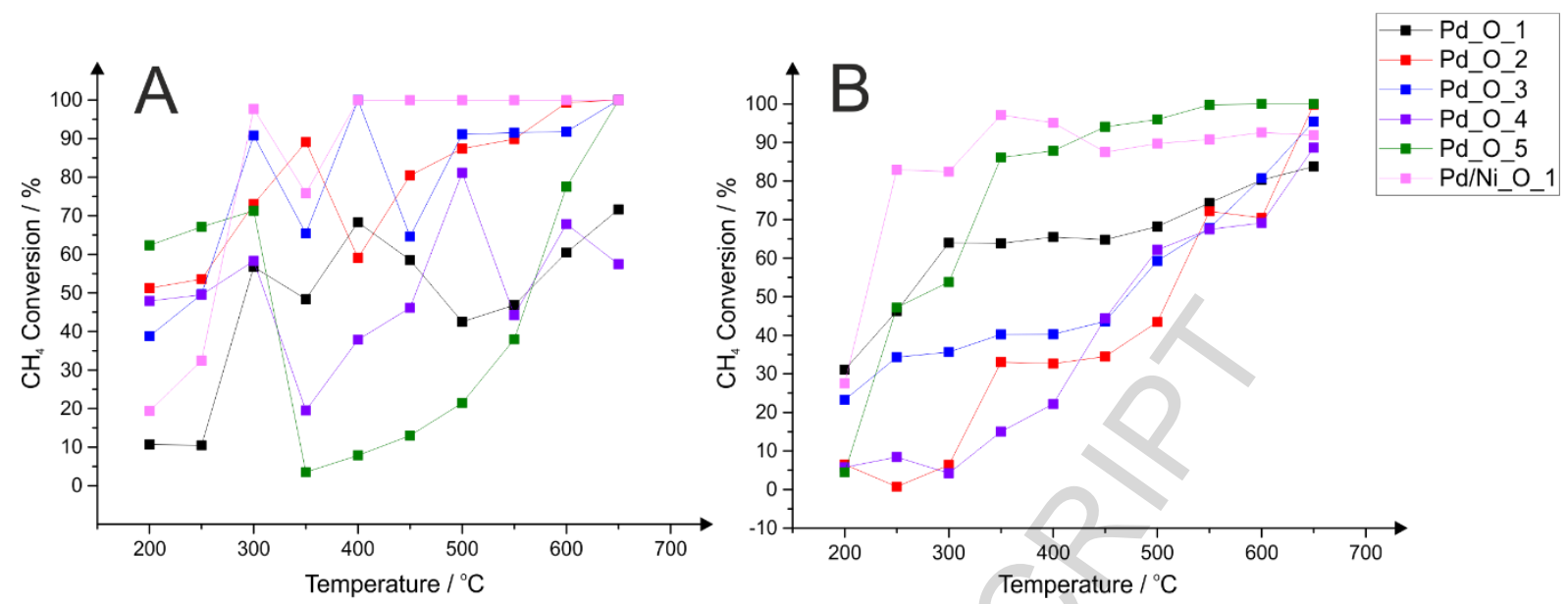
Figure 3. Methane oxidation of Ni based catalysts as reduced metal (A) and oxidised metal (B).
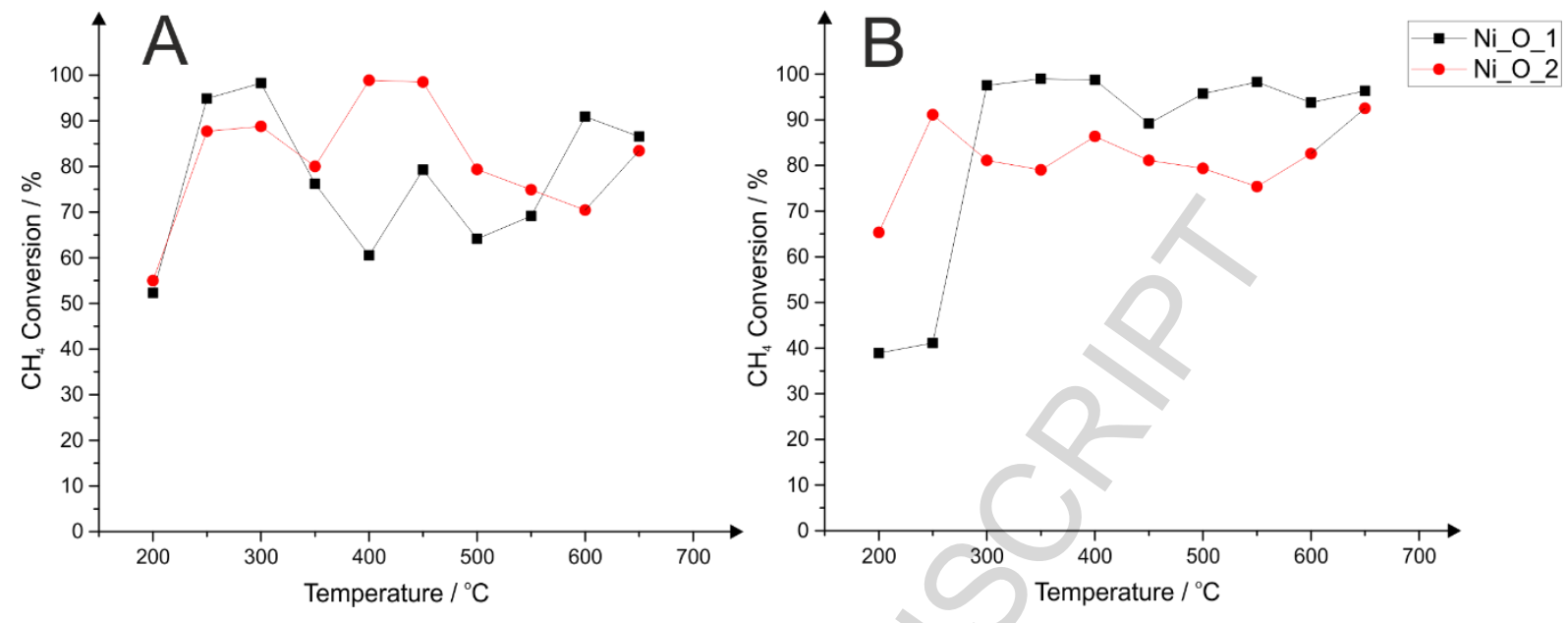
Table 1. Summary of preparation methods of the catalysts.

Sample name

$P d \_O 1$

$P d \_O \_2$

$P d \_O \_3$

$P d \_O \_4$

$P d \_O 5$

Ni_O_l

Ni_O_2

$N i / P d \_O \_1$
HAP

Tween 60

Tween60+ $\mathrm{C}_{12} \mathrm{EO}_{9}$

$\mathrm{C}_{12} \mathrm{EO}_{9}$

Carbon nanorods

Carbon nanorods

Tween60+C ${ }_{12} \mathrm{EO}_{9}$

Tween 60

Carbon nanorods
Metal precursor

$\mathrm{PdCl}_{2}$

$\mathrm{PdCl}_{2}$

$\mathrm{Pd}\left(\mathrm{NO}_{3}\right)_{2}$

$\mathrm{Pd}\left(\mathrm{NO}_{3}\right)_{2}$

$\mathrm{PdCl}_{2}$

$\mathrm{NiNO}_{3}$

$\mathrm{NiO}$

$\mathrm{Pd}\left(\mathrm{NO}_{3}\right)_{2}, \mathrm{NiNO}_{3}$ 
Table 2. BET surface areas of the catalysts with corresponding metal loading by EDX.

\begin{tabular}{|c|c|c|}
\hline Sample name & $\begin{array}{c}\text { BET surface area } \\
\qquad / \mathrm{m}^{2} \mathrm{~g}^{-1}\end{array}$ & $\begin{array}{c}\text { EDX average metal loading } \\
/ w t \%\end{array}$ \\
\hline$P d \_O \_1$ & 42.1 & $3.31 \pm 0.6$ \\
\hline$P d \_O-2$ & 114.6 & $2.98 \pm 0.4$ \\
\hline$P d_{-} O_{-} 3$ & 53.4 & $3.19 \pm 0.9$ \\
\hline$P d_{-} O_{-} 4$ & 59.5 & $2.09 \pm 0.5$ \\
\hline $\mathrm{Pd}_{-}^{-} \mathrm{O}_{-} 5$ & 67.4 & $2.03 \pm 0.4$ \\
\hline$P d / N i_{-} O_{-} 1$ & 72.6 & $\begin{array}{l}\mathrm{Pd}: 2.39 \pm 0.6 \\
\mathrm{Ni}: 1.93 \pm 0.8\end{array}$ \\
\hline$N i_{-} O_{-} 1$ & 16.5 & $5.94 \pm 0.5$ \\
\hline$N i \_O \_2$ & 19.7 & $5.24 \pm 0.7$ \\
\hline
\end{tabular}




\section{References}

[1] B. Christian Enger, R. Lødeng, A. Holmen, A review of catalytic partial oxidation of methane to synthesis gas with emphasis on reaction mechanisms over transition metal catalysts, Applied Catalysis A: General, 346 (2008) 1-27.

[2] P. Tang, Q. Zhu, Z. Wu, D. Ma, Methane activation: the past and future, Energy \& Environmental Science, 7 (2014) 2580-2591.

[3] M. Usman, W.M.A. Wan Daud, H.F. Abbas, Dry reforming of methane: Influence of process parameters-A review, Renewable and Sustainable Energy Reviews, 45 (2015) 710-744.

[4] Francisco Ivars, J.M.L. Nieto, Handbook of Advanced Methods and Processes in Oxidation Catalysis, Imperial College Press, London, 2014.

[5] N. Pal, A. Bhaumik, Mesoporous materials: versatile supports in heterogeneous catalysis for liquid phase catalytic transformations, RSC Advances, 5(2015) 24363-24391.

[6] A. K. Datye, J. Bravo, T.R. Nelson, P. Atanasova, M. Lyubovsky, L. Pfefferle, Catalyst microstructure and methane oxidation reactivity during the $\mathrm{Pd} \leftrightarrow \mathrm{PdO}$ transformation on alumina supports, Applied Catalysis A: General, 198 (2000) 179-196.

[7] T.R. Baldwin, R. Burch, Catalytic combustion of methane over supported palladium catalysts, Applied Catalysis, 66 (1990) 359-381.

[8] K.I. Fujimoto, F.H. Ribeiro, M. Avalos-Borja, E. Iglesia, Structure and Reactivity of PdOx/ZrO2Catalysts for Methane Oxidation at Low Temperatures, Journal of Catalysis, 179 (1998) 431-442.

[9] R.J. Farrauto, M.C. Hobson, T. Kennelly, E.M. Waterman, Catalytic chemistry of supported palladium for combustion of methane, Applied Catalysis A: General, 81(1992) 227-237.

[10] X. Zhang, C.S.M. Lee, D.M.P. Mingos, D.O. Hayward, Oscillatory behaviour during the oxidation of methane over palladium metal catalysts, Applied Catalysis A: General, 240 (2003) 183-197.

[11] S. Sugiyama, Y. Iguchi, H. Nishioka, T. Minami, T. Moriga, H. Hayashi, J.B. Moffat, Effects of the Thermal Stability and the Fine Structure Changes of Strontium Hydroxyapatites Ion-Exchanged with Lead on Methane Oxidation in the Presence and Absence of Tetrachloromethane, Journal of Catalysis, 176 (1998) 25-34.

[12] S. Sugiyama, T. Minami, T. Moriga, H. Hayashi, J.B. Moffat, Calcium-Lead Hydroxyapatites: Thermal and Structural Properties and the Oxidation of Methane, Journal of Sol id State Chemistry, 135 (1998) 86-95.

[13] S. Sugiyama, T. Minami, H. Hayashi, M. Tanaka, J.B. Moffat, Surface and Bulk Properties of Stoichiometric and Nonstoichiometric Strontium Hydroxyapatite and the Oxidation of Methane, Journal of Solid State Chemistry, 126 (1996) 242-252.

[14] S. Sugiyama, T. Minami, H. Hayashi, M. Tanaka, N. Shigemoto, J.B. Moffat, Partial Oxidation of Methane to Carbon Oxides and Hydrogen on Hydroxyapatite: Enhanced Selectivity to Carbon Monoxide with Tetrachloromethane, Energy \& Fuels, 10 (1996) 828-830.

[15] J. Kamieniak, P.J. Kelly, C.E. Banks, A.M. Doyle, Mechanical, pH and Thermal Stability of Mesoporous Hydroxyapatite, Journal of Inorganic and Organometallic Polymers and Materials, (2017).

[16] J. Kamieniak, A.M. Doyle, P.J. Kelly, C.E. Banks, Novel Synthesis of Mesoporous Hydroxyapatite using Carbon Nanorods as a Hard-Template, Ceramics International.

[17] M. Uota, H. Arakawa, N. Kitamura, T. Yoshimura, J. Tanaka, T. Kijima, Synthesis of High Surface Area Hydroxyapatite Nanoparticles by Mixed Surfactant-Mediated Approach, Langmuir, 21 (2005) 4724-4728.

[18] S. Rujitanapanich, P. Kumpapan, P. Wanjanoi, Synthesis of Hydroxyapatite from Oyster Shell via Precipitation, Energy Procedia, 56 (2014) 112-117.

[19] J. Kamieniak, E. Bernalte, C. Foster, A. Doyle, P. Kelly, C. Banks, High Yield Synthesis of Hydroxyapatite (HAP) and Palladium Doped HAP via a Wet Chemical Synthetic Route, Catalysts, 6 (2016) 119. 
[20] Z. Boukha, M. Kacimi, M. Ziyad, A. Ensuque, F. Bozon-Verduraz, Comparative study of catalytic activity of Pd loaded hydroxyapatite and fluoroapatite in butan-2-ol conversion and methane oxidation, Journal of Molecular Catalysis A: Chemical, 270 (2007) 205-213.

[21] A. Indra, C.S. Gopinath, S. Bhaduri, G. Kumar Lahiri, Hydroxyapatite supported palladium catalysts for Suzuki-Miyaura cross-coupling reaction in aqueous medium, Catalysis Science \& Technology, 3(2013) 1625-1633.

[22] K. Asami, T. Shikada, K. Fujimoto, H. Tominaga, Oxidative coupling of methane over lead oxide catalyst: kinetic study and reaction mechanism, Industrial \& Engineering Chemistry Research, 26 (1987) 2348-2353.

[23] E. Baktash, P. Littlewood, R. Schomäcker, A. Thomas, P.C. Stair, Alumina coated nickel nanoparticles as a highly active catalyst for dry reforming of methane, Applied Catalysis B:

Environmental, 179 (2015) 122-127. 


\section{Highlights}

- $\mathrm{Pd}, \mathrm{Ni}$ and $\mathrm{Pd} / \mathrm{Ni}$-doped mesoporous HAP are highly active towards $\mathrm{CH}_{4}$ oxidation from $200^{\circ} \mathrm{C}$

- $\mathrm{Pd} / \mathrm{Ni}$-HAP obtain remarkable activity converting $100 \%$ of $\mathrm{CH}_{4}$ at $300^{\circ} \mathrm{C}$

- Methane oxidation proceeds via redox cycle between metal and metal oxide

- $\quad$ Adsorbed lattice oxygen takes direct part in the catalysis reaction 